\title{
An Alternative Technique to Reveal Polysaccharides in Toxoplasma gondii Tissue Cysts
}

\author{
Erick Vaz Guimarães, Laís de Carvalho*, Helene Santos Barbosa ${ }^{+}$
}

\begin{abstract}
Laboratório de Ultra-estrutura Celular, Departamento de Ultra-estrutura e Biologia Celular, Instituto Oswaldo Cruz-Fiocruz, Av. Brasil 4365, 21045-900 Rio de Janeiro, RJ, Brasil *Laboratório de Cultura de Células, Departamento de Histologia e Embriologia, Universidade do Estado do Rio de Janeiro, Rio de Janeiro, RJ, Brasil
\end{abstract}

Ultrathin sections of tissue cysts isolated from the brain of Toxoplasma gondii infected mice were submitted to two different methodologies derived from the periodic acid - Schiff's reagent (PAS) technique. The use of osmium tetroxide vapor as a developing agent of the aldehyde oxidation to reveal polysaccharides with periodic acid resulted in positive reaction in amylopectin granules in bradyzoites, as well as in the wall and matrix of the cysts, with excellent increment of the ultrastructural morphology. This technique can be used for study of $\mathrm{T}$. gondii-host cell intracellular cycle, the differentiation tachyzoite-bradyzoite, and also for the formation of cysts into the host cells.

Key words: Toxoplasma gondii - amylopectin granules - tissue cysts - ultrastructural cytochemistry

Infection with the protozoan parasite Toxoplasma gondii is endemic throughout the world. This obligate intracellular parasite is able to persist in its hosts by differentiating from the replicative tachyzoite stage into cysts forming latent bradyzoites. The reversible stage differentiation in $T$. gondii makes it an interesting model system of protozoan differentiation. The energy requirements and biosynthetic substrates of coccidian parasites are mostly dependent on carbohydrate metabolism. The reserve of polysaccharides in $T$. gondii is found in amylopectin granules, which are scarce or absent in tachyzoites, but abundant in bradyzoites (reviewed in Dubey et al. 1998, Speer et al. 1999). Bradyzoites enriched with amylopectin granules are colored in red when stained with the periodic acid - Schiff reagent (PAS) technique (reviewed in Dubey et al. 1998) besides being less susceptible to the destruction by proteolytic enzymes, as compared with the tachyzoites (Jacobs et al. 1960, Dubey 1998). In this report we present the characterization of these amylopectin granules in $T$. gondii tissue cysts by two alternative ultrastructural cytochemistry methodologies.

\section{MATERIALS AND METHODS}

Tissue cysts - C57BL/6 mice were infected intraperitoneally with 50-100 cysts of T. gondii ME-49 strain, an avirulent cyst-forming strain. Brains from 4-8 weeks

Financial support: Conselho Nacional de Desenvolvimento Científico e Tecnológico, Fundação Carlos Chagas Filho de Amparo à Pesquisa do Estado do Rio de Janeiro, Universidade do Estado do Rio de Janeiro, and Instituto Oswaldo CruzFiocruz

${ }^{+}$Corresponding author. Fax: +55-21-2260.4434. E-mail: helene@ioc.fiocruz.br

Received 16 June 2003

Accepted 10 September 2003 infected mice were colleted, washed in phosphate buffered saline (PBS) and homogenized in 30\% Dextran (w/v) in Hank's balanced salt solution (HBSS) by 5 passages through an 18-23 gauge needle at a concentration of no more than $1 \mathrm{brain} / 2.5 \mathrm{ml}$. This solution was centrifuged at $3000 \mathrm{~g}$ for $10 \mathrm{~min}$ and the pellet containing the tissue cysts was resuspended in HBSS (Freyre 1995, Popiel et al. 1996).

Transmission electron microscopy - Isolated cysts were fixed for $1 \mathrm{~h}$ at $4{ }^{\circ} \mathrm{C}$ with $2.5 \%(\mathrm{v} / \mathrm{v})$ glutaraldehyde in $0.1 \mathrm{M} \mathrm{Na}$-cacodylate buffer ( $\mathrm{pH}$ 7.2). After fixation, the cysts were washed in PBS and post-fixed for $30 \mathrm{~min}$ at room temperature with $1 \% \mathrm{OsO}_{4}$ in $0.1 \mathrm{M}$ cacodylate buffer containing $5 \mathrm{mM} \mathrm{CaCl}_{2}$ and $3.5 \%$ sucrose. Cells were then washed in the same buffer, dehydrated in acetone and embedded in PolyBed 812. Unstained thin sections were processed for cytochemistry.

Ultrastructural cytochemistry - To characterize the polysaccharides expression (amylopectin granules) in tissue cysts, we have used two methodologies. Thin sections were colleted on gold grids, oxidized for $20 \mathrm{~min}$ with $1 \%$ periodic acid, quickly washed twice in distilled water, and finally incubated for $72 \mathrm{~h}$, in humid chamber at room temperature, in $2 \%$ thiocarbohydrazide $(\mathrm{TCH})$ diluted at $20 \%(\mathrm{v} / \mathrm{v})$ in acetic acid. These grids were washed successively in decreasing concentrations of acetic acid $(10 \%, 5 \%, 3 \%$, and $1 \%)$ for $1 \mathrm{~min}$ each. The polysaccharide revelation was made by incubating the grids for $30 \mathrm{~min}$ in an aqueous solution with $1 \%$ silver proteinate.

In the second methodology, after the steps described above, the carbohydrate revelation was accomplished by incubation of tissue cysts on grids with osmium tetroxide vapor for $1 \mathrm{~min}$. Using both methodologies after the revelation, these grids were quickly washed once with distilled water, followed by another wash for $10 \mathrm{~min}$. Controls experiments of the reaction were obtained by the omission of the oxidation step by the periodic acid, or the treatment of the cysts with $\mathrm{TCH}$ to guarantee that the reaction has been produced by free aldehydes, or by reaction of TCH with the biological material, respectively. Other control was made by omission of the osmium 

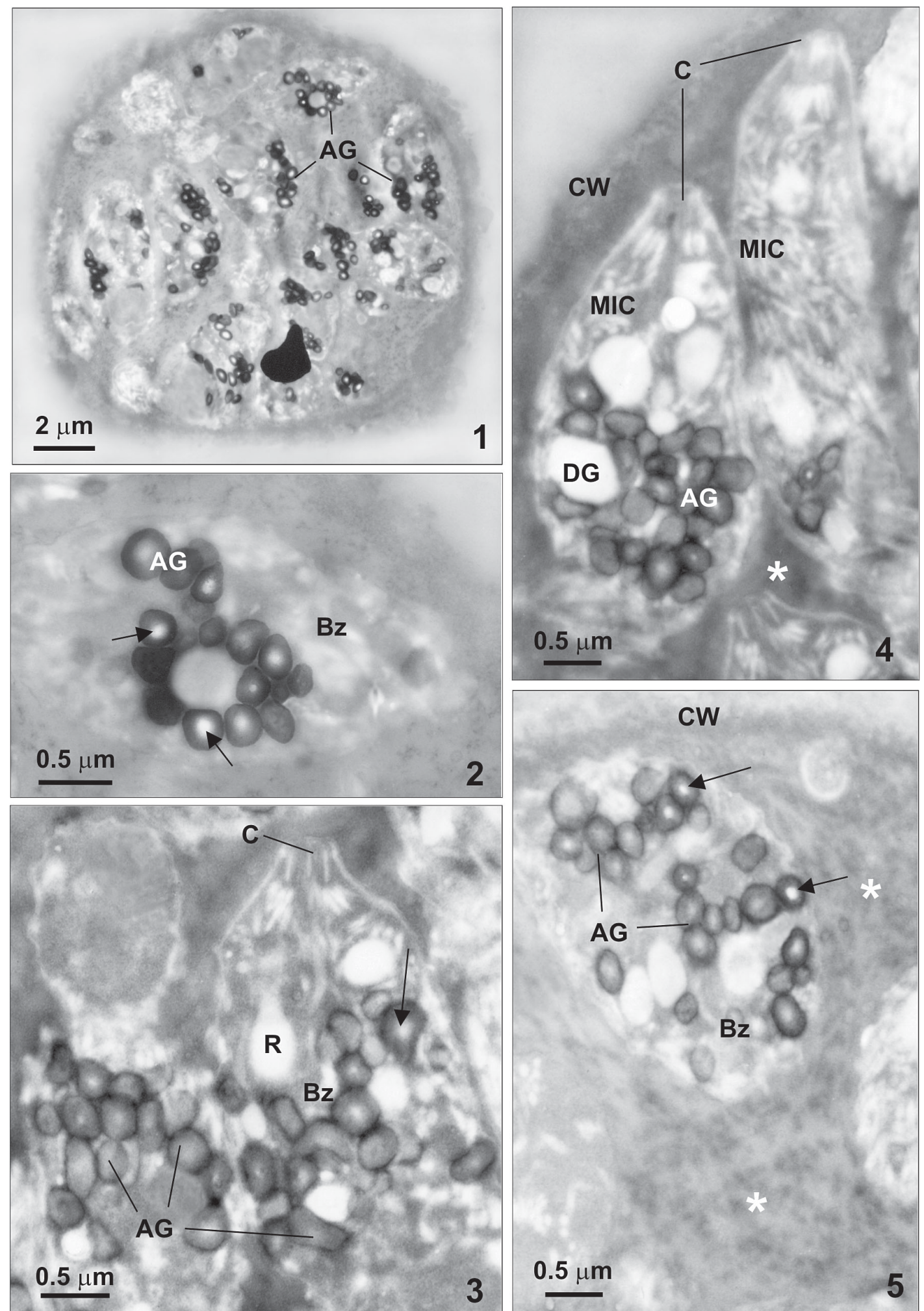

Figs 1-2: reaction product for the Thièry technique employing silver proteinate as developing agent of reaction product. Fig. 1: ultrathin section of a whole cyst containing parasites, the most presenting the electrondense reaction product located in cytoplasmatic organelles, indicative of the presence of amylopectin granules (AG). Fig. 2: detail of the reaction product in AG inside a bradyzoite (Bz). Figs 3-5: modification of the Thièry technique using the osmium vapor in Toxoplasma gondii tissue cysts. Fig. 3: detail showing the AG and the ultrastructural morphology of the parasites (Bz). Some amylopectin granules present the central area lacking the reaction product (arrow); R: rhoptria; C: conoid. Fig. 4: aspects of the reaction product for the osmium vapor showing intense reactivity in AG and in the cystic wall and matrix. A contrast reversion was observed with this technique, allowing a detailed visualization of the structures and organelles of the parasites; CW: cystic wall; MIC: microneme; DG: dense granules; * : matrix. Fig. 5: reaction product observed in AG and in *, appearing as increase in electrondensity, indicative of the presence of glycoconjugates. 
tetroxide. Finally, the sections were examined unstained in a Zeiss EM 10C transmission electron microscope.

\section{RESULTS}

Both methodologies used in the current work revealed polysaccharides in bradyzoites forms of $T$. gondii tissue cysts located in electrondense oval bodies, the amylopectin granules. The granules were observed in large amount mainly in the middle-posterior portion of the parasites (Figs 1-5). Fig. 1 shows the reaction product when silver proteinate was used as a developing agent of the aldehyde reactivity. The reaction product was intense, presenting also a very fine granular deposit in the cyst matrix and in the cyst wall (Figs 1,2). This reaction was observed in most intracystic parasites, although some parasites presented no reaction product or small intracellular granules (Fig. 1).

When the osmium tetroxide vapor was used as a developing agent for the reaction, besides increasing the electrondensity of the amylopectin granules inside the cysts, it allowed an excellent visualization of the structures of the parasites, such as internal membranes, conoid, rhoptries and micronemes, which acquired a negative contrast (Figs 3-5). Some granules presented the central area without reaction product (Figs 2, 3, 5). The wall, the granular region, and the matrix of the cysts also showed enhanced reactivity, although with lower intensity (Fig. 5 ). No reaction product was visualized in cells when $\mathrm{TCH}$, osmium or periodic acid was omitted (data not shown).

\section{DISCUSSION}

The alternative method for the detection of vic diols in carbohydrates used here, showed to be sensitive and selective, additionally improving the quality of the parasite ultrastructural morphology. The two ultrastructural cytochemistry techniques used in this study to detect polysaccharides and glycoproteins in $T$. gondii tissue cysts using TCH to detect aldehydes produced by the periodic acid are derived from reagent of PAS technique routinely used in light microscopy and adapted for transmission electron microscopy by Hanker et al. (1964) and Thièry (1967). The Hanker's method used the osmium vapor to reveal the final product of reaction. Later, Thièry (1967) adapted the technique, facilitating the treatment of ultra-thin sections of specimens embedded in hydrophobic conditions (for example, epoxy resins), obtaining better results in the revelation of the reaction with the use of metallic protein, the silver proteinate. With the introduction of the silver proteinate, the osmium technique was abandoned because it produces less contrast than the silver, which is also less toxic to the operator. A drawback of the silver use is, however, that the silver grains form precipitates that hinder a clean reaction, and thus the reaction needs to be repeated several times, until a clean reaction can be obtained.

Due to the problems with the use of silver, we have chosen trying to use the osmium technique, and the quality of our results was superior than that obtained with the silver proteinate. The use of osmium allowed to obtain images of high resolution with great contrast of the structural cell components, evidentiating besides the amylopectin granules, the cellular membranes, nucleus, conoid, rhoptries, dense granules and micronemes. This facilitated the structural visualization of the parasites, without the presence of precipitates and without affecting the revelation of the final reaction product.

The method used in this study, can be applied to distinguish between bradyzoite and tachyzoite forms inside the tissue cysts, due to the presence of large amount of amylopectin granules in the bradyzoites, responsible for great polysaccharides accumulation and as material of energy reserve in these parasites. The osmium method showed to be sensitive to delimitate the matrix and cystic wall. Our methodology, besides the above-described advantages, can be used for studies on the interaction between bradyzoites and skeletal muscle cell or other host cells, improving the follow-up of intracellular cycle of $T$. gondii, its reversible differentiation (tachyzoitebradyzoite), and also during the formation of latent bradyzoites in cysts into the host cells, in vitro.

\section{ACKNOWLEDGEMENTS}

To Dr Ricardo T Gazzinelli (Universidade Federal de Minas Gerais), for supplying the $T$. gondii ME-49 strain, to Dr Maurilio José Soares for critically reading this manuscript, and Genésio L Faria, Ismael CS Gomes, and José L Faria for their excellent technical assistance.

\section{REFERENCES}

Dubey JP 1998. Re-examination of resistance of Toxoplasma gondii tachyzoites and bradyzoites to pepsin and trypsin digestion. Parasitology 116: 43-50.

Dubey JP, Lindsay DS, Speer CA 1998. Structures of Toxoplasma gondii tachyzoites, bradyzoites, and sporozoites and biology and development of tissue cysts. Clin Microbiol Rev 11: 267-299.

Freyre A 1995. Separation of toxoplasma cysts from brain tissue and liberation of viable bradyzoites. J Parasitol 81 : 1008-1010.

Hanker JS, Seaman AR, Weiss LO, Ueno H, Bergman RA, Seligman AM 1964. Osmiophilic reagents: new cytochemical principle for light and electron microscopy. Science 146: 1039-1043.

Jacobs L, Remington JS, Melton ML 1960. The resistance of the encysted form of Toxoplasma gondii. J Parasitol 46: 11-21.

Popiel I, Gold MC, Booth KS 1996. Quantification of Toxoplasma gondii bradyzoites. J Parasitol 82: 330-332.

Speer CA, Dubey JP, McAllister MM, Blixt JA 1999. Comparative ultrastructure of tachyzoites, bradyzoites, and tissue cysts of Neospora caninum and Toxoplasma gondii. Int J Parasitol 29: 1509-1519.

Thièry JP 1967. Mise en evidence des polysaccharides sur coupes fines en microscopie électronique. J Microscopie 6: $987-1018$. 